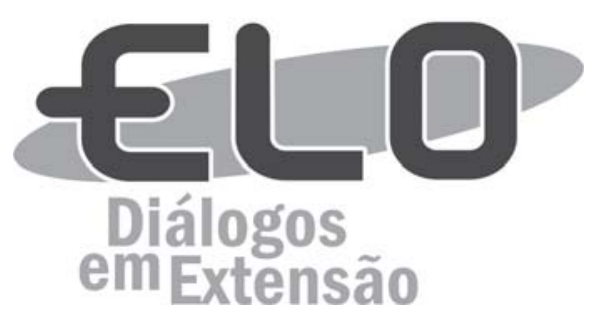

\title{
Plantas medicinais e a extensão universitária como estratégia de fortalecimento de uma cooperativa de agricultores no Leste Fluminense
}

Ronald de Figueiredo Nascimento ${ }^{1}$, Vitória Borzino Cordeiro Nunes² ${ }^{2}$, Flávia dos Santos Dias ${ }^{3}$, Jamylle M. Marques, Thelma de Barros Machado

\begin{abstract}
Resumo: Neste trabalho são descritas as atividades do Grupo PET Farmácia Viva junto a comunidades de agricultores familiares da Cooperativa UNIVERDE de Nova Iguaçu-RJ. Essas comunidades se depararam com diversas dificuldades para prosseguir com suas atividades agrícolas em modelo agroecológico após o encerramento do Programa de Agricultura Familiar sobre Dutos da Transpetro, em 2008. Por meio de um modelo de gestão participativa, o PET Farmácia Viva realizou um planejamento estratégico que visava oferecer capacitações técnicas demandadas pela própria comunidade, entre outros objetivos, tendo como princípio básico para o atingimento das metas, a troca de saberes. Pôde-se identificar, como resultados da atuação do PET Farmácia Viva, a consolidação de suas principais tarefas em disseminar o conhecimento e fortalecer a Extensão Universitária com impacto direto na sociedade, uma vez que foi verificado a partir do desempenho dos grupos familiares envolvidos, que sua renda familiar foi aumentada, bem como houve um empoderamento dos mesmos ao longo desse processo. Concluiu-se que as atividades de extensão, além dos inúmeros benefícios e experiências enriquecedoras ofertados aos membros da comunidade acadêmica, contribuem para o desenvolvimento da sociedade. Os recursos disponibilizados para a realização de projetos de extensão possibilitam à Universidade atuar na formação de uma sociedade mais justa e igualitária, levando oportunidades à pessoas que vivem em realidades muito distintas. Com otimização das técnicas de produção e administração dos agricultores das comunidades de Geneciano Luz e Figueira, tais agricultores se empoderam e se tornam aptos para se organizar e coordenar a produção. Os estudantes conseguem articular seus conhecimentos e vivências da academia para o campo, dialogar com os pequenos produtores, além de estabelecer uma relação de confiança com todos os envolvidos no projeto.
\end{abstract}

Palavras-chave: Agricultura Familiar. Agroecologia. Cooperativismo. Extensão Universitária.

Área Temática: Meio Ambiente. Políticas Públicas. Ruralidade. Trabalho.

\section{Medicinal plants and university outreach as a strategy to strengthen a farmer's cooperative from East Fluminense}

Abstract: In this paper the activities of the PET Farmácia Viva Group are described, together with the families of farmers from the Cooperative UNIVERDE of Nova Iguaçu-RJ. These communities encountered several difficulties to continue their agricultural activities in an agro-ecological model after the end of the Transpetro Family Duct Farming Program in 2008. By means of a participatory management model, the PET Farmácia Viva Group carried out a strategic planning that aimed at offering technical skills demanded by the community itself, among other objectives, having as basic principle for the achievement of goals, the

\footnotetext{
${ }^{1}$ Universidade Federal de Minas Gerais, Escola de Engenharia, Departamento de Engenharia Química. Av. Presidente Antônio Carlos, 6627. CEP: 31270901 ; Técnico Administrativo e Ex-bolsista do Programa PET Farmácia Viva. (031) 973912689; ronaldf@ufmg.br

${ }^{2}$ Universidade Federal Fluminense, Graduanda em Farmácia e bolsista do Programa PET Farmácia Viva.

${ }^{3}$ Universidade Federal Fluminense; Graduanda em Engenharia Agrícola e Ambiental e bolsista do Programa PET Farmácia Viva.

${ }^{4}$ UniversidadeFederal Fluminense, Faculdade de Farmácia, Laboratório de Controle Físico-Químico. Docente na Faculdade de Farmácia e Tutora do Grupo PET Farmácia Viva.
} 
exchange of knowledge. As a result, it was possible to identify the consolidation in disseminating knowledge and strengthening the University Extension with a direct impact on society, once it was verified from the performance of the family groups involved an increase in their income and an empowerment throughout this process. Extension activities, besides the numerous benefits and enriching experiences offered to the members of the academic community, contribute to the development of society. The resources made available for the development of extension projects allow the University to act in the formation of a more fair and equal society, bringing opportunities to people living in very different realities. With optimization of the production and management techniques in the communities of farmers of Geneciano Luz and Figueira, they are empowered and able to organize and coordinate production. Students are able to articulate their knowledge and experiences from academia to the field, to dialogue with small producers, and to establish a relationship of trust with all those involved in the project.

Keywords: Family Farming. Agroecology. Cooperativism. Extension.

\section{Plantas medicinales y la extensión universitaria como estrategia de fortalecimiento de una cooperativa de agricultores en el Este Fluminense}

Resumen: En este trabajo se describen las actividades del Grupo PET Farmacia Viva junto a comunidades de agricultores familiares de la Cooperativa UNIVERDE de Nova Iguaçu-RJ. Las comunidades viven diversas dificultades para proseguir con sus actividades agrícolas en modelo agroecológico especialmente tras el cierre del Programa de Agricultura Familiar sobre los Ductos de Transpetro en el año 2008. Considerando un modelo de gestión participativa, el PET Farmacia Viva realizó un planeamiento estratégico con el fin de ofrecer capacidades técnicas demandadas por la propia comunidad, entre otros objetivos, teniendo como principio básico para el logro de las metas, el intercambio de saberes. Los resultados de la actuación del PET Farmacia Viva han sido la consolidación de sus principales tareas en diseminar el conocimiento y fortalecer la Extensión Universitaria con impacto directo en la sociedad, una vez que fue verificado, apartir del desempeño de los grupos familiares implicados, que sus rentas se ha incrementado, así como un empoderamiento de los mismos a lo largo de este proceso. Se concluyó que las actividades de extensión, además de los innumerables beneficios y experiencias enriquecedoras ofrecidos a los miembros de la comunidad académica, contribuyen al desarrollo de la sociedad. Los recursos disponibles para la realización de proyectos de extensión posibilitan a la Universidad actuar en la formación de una sociedad más justa e igualitaria, produciendo oportunidades a personas que viven en realidades muy distintas. Con la optimización de las técnicas de producción y administración de los agricultores de las comunidades de Geneciano Luz y Figueira, los agricultores se empoderan y se tornanhacen aptos para organizarse y coordinar la producción. Los estudiantes consiguen articular sus conocimientos y vivencias de la academia Universidad para el campo, es decir, se hacen aptos a dialogar con los pequeños productores, además de crear una relación de confianza con todos los involucrados en el proyecto.

Palabras clave: Agricultura familiar. Agroecología. Cooperativismo. Extensión.

\section{Introdução}

Contexto histórico do "PAF Dutos - Programa de Agricultura Familiar em Faixa de Dutos" e criação da cooperativa Univerde.

O município de Nova Iguaçu, está localizado na "Baixada Fluminense", pertence à região metropolitana do Rio de Janeiro, e é distante $29,6 \mathrm{~km}$ da capital. A cidade de Nova Iguaçu, considerada o maior município da Baixada Fluminense, possui áreas de extrema pobreza e grandes desigualdades sociais. Em contraste, possui diversos recursos de interesses naturais e artificiais, porém com muita deficiência de infraestrutura. Esse cenário dificulta ainda mais o desenvolvimento da população carente e, nesse âmbito, o agricultor também fica desamparado pela falta de uma legislação específica que contemple o desenvolvimento da agricultura (LANÇA, 2013).

O Projeto "PAF Dutos" foi instituído em 2005 na Baixada Fluminense, incluindo quatro áreas entre os Municípios de Nova Iguaçu e Duque de Caxias (SIQUEIRA, 2009). O projeto PAF Dutos originou-se de um compromisso firmado entre a Petrobras e o Ministério Público Estadual do Rio de Janeiro após uma série de acidentes que ocasionaram vazamentos de dutos da Petrobras na Baía de Guanabara. Para tanto, a empresa assinou o TCAA (Termo de Compromisso para Ajuste Ambiental) com os objetivos de remodelar o sistema de dutos e a gestão dos riscos (LANÇA, 2013). 
Visando cumprir com o acordo, ao mesmo tempo em que a Petrobras assinava o TCAA, a Transpetro, junto com o Instituto Terra de Preservação Ambiental e Entidade Ambientalista Onda Verde (organizações não governamentais) integrados com o Programa Nacional Fome Zero criaram o projeto PAF-Dutos (LANÇA, 2013) com o objetivo de se utilizar o solo das áreas de faixa de dutos, os quais não podem ser perfurados, para a implementação de hortas familiares em modelo agroecológico visando, além de incrementar a renda das comunidades participantes, a conservação dos dutos. (PETROBRAS, 2007)

Cerca de 100 famílias selecionadas na região de Nova Iguaçu e Duque de Caxias, foram contempladas com os insumos necessários para a implementação da horta (sementes e mudas), equipamentos e ferramentas, energia elétrica e caminhões, além de uma equipe multidisciplinar para assessoramento técnico e organizacional. (PETROBRAS, 2007)

Em 2008, com o final do Projeto PAF Dutos, houve êxodo de diversas famílias, mesmo porque no Plano Diretor de Nova Iguaçu, não se delimitou quais áreas eram Iguaçuanas (LANÇA, 2013) e essa dificuldade em delimitar o espaço, provavelmente foi um grande motivo para inviabilizar a permanência dos pequenos produtores naquela região. Dezesseis famílias das comunidades de Geneciano Luz e Figueira, NI, no entanto, se uniram e criaram a UNIVERDE (Cooperativa de Agricultores Familiares de Agricultura Agroecológica).

\section{Extensão universitária}

O artigo 207 da Constituição Federal de 1988 afirma que ensino, pesquisa e extensão formam a base indissociável do ensino superior no Brasil. Na extensão, membros da Universidade atuam em outros locais, além da instituição, divulgando o saber científico e aplicando-o na prática, com benefícios para ambas as partes.

As atividades de extensão universitária são de importância considerável para o desenvolvimento acadêmico, psicológico e humano dos alunos e tutores envolvidos, trazendo à luz discussões de diferentes situações do cotidiano de uma comunidade, que pode ser um bairro ou um município. Para as atividades, é proposta a inserção de docentes e discentes, os quais, muitas vezes, ficam imersos em situações novas e inesperadas e precisam elaborar soluções rápidas para as mais diferentes situações. Assim, o caráter extensionista do projeto é levar o conhecimento adquirido no meio acadêmico aos membros da comunidade por meio de discussões e debates. Ao ouvirem e se integrarem com membros da comunidade, os docentes e discentes são tocados pela sabedoria popular, numa troca contínua e desejável de saberes. De um lado, os alunos e professores podem trazer a colaboração de seus projetos de pesquisa e desenvolvimento, suas metodologias e todos os recursos proporcionados pela infraestrutura da Universidade; do outro, os membros da comunidade compartilham seus conhecimentos adquiridos pela tradição, por suas vivências e observações, pelo contato com outros cidadãos e, também, contatos anteriores com membros da academia. Esses são, por sua vez, representantes do panorama atual de determinada situação que recebe a intervenção das atividades extensionistas.

Há influência direta dos projetos de extensão no desenvolvimento científico, cultural e socioeconômico de uma comunidade. Todo o conhecimento adquirido na Universidade deve ser passado da forma mais simples possível, pois o objetivo principal é a troca de conhecimentos e saberes. No entanto, para que todas essas atividades possam ter êxito, é importante fazer um planejamento de objetivos, metas a cumprir, prazos e recursos necessários. O financiamento desses recursos é um parâmetro muito importante, uma vez que ele pode limitar os projetos a serem implementados e definir o alcance das atividades. Assim, o custeio das atividades de extensão pode ser da própria Universidade, de uma organização externa ou por meio de parcerias entre elas.

\section{O Programa de Educação Tutorial (PET) Farmácia Viva e sua inserção nas comunidades}

O Programa de Educação Tutorial (PET), instituído, oficialmente, pela lei $\mathrm{n}^{\circ}$ 11.180/2005 é financiado pelo Ministério da Educação (MEC) por meio da Secretaria de Ensino Superior (SESu). É constituído por estudantes de graduação (bolsistas) e um professor-tutor do grupo e se baseia nos pilares ensino, pesquisa, extensão e educação tutorial. Os grupos podem contar, ainda, com alunos voluntários e professores colaboradores. A relação dentro dos grupos PET é de companheirismo, troca de experiências e aprendizado, onde todos estão aptos a aprender e a ensinar e, principalmente, a auxiliar os membros do grupo no que for possível. É uma oportunidade inigualável de aprendizado de 
trabalho em grupo, onde a colaboração de todos é um diferencial para o sucesso dos projetos implementados. Os tutores coordenam projetos individuais e coletivos, e atuam como guias para os alunos, que possuem ideias próprias para projetos e atividades extracurriculares a serem realizadas e podem contar com o tutor para colocá-las em prática, fazer modificações e estabelecer contatos. Os alunos podem concorrer a uma vaga no grupo PET mediante processo seletivo, bem como o tutor.

Entre os objetivos de um grupo PET, destacam-se: desenvolver atividades acadêmicas com padrões de excelência, mediante grupos de aprendizagem tutorial de natureza coletiva e interdisciplinar; contribuir para a elevação da qualidade da formação acadêmica dos alunos de graduação; estimular a formação de profissionais e docentes de elevada qualificação técnica, científica, tecnológica e acadêmica; formular novas estratégias de desenvolvimento e modernização do ensino superior no país; estimular o espírito crítico, bem como a atuação profissional pautada pela cidadania e pela função social da educação superior; introduzir novas práticas pedagógicas na graduação; contribuir para a consolidação e difusão da educação tutorial como prática de formação na graduação; e contribuir com a política de diversidade na instituição de ensino superior (IES), por meio de ações afirmativas em defesa da equidade socioeconômica, étnico-racial e de gênero.

O grupo PET Farmácia Viva, instituído em 2010 na Faculdade de Farmácia da Universidade Federal Fluminense (UFF), busca implementar o uso de plantas medicinais no âmbito do SUS garantindo às comunidades o acesso seguro e o uso Racional de Plantas Medicinais e Fitoterápicos. As atividades planejadas para o grupo têm como objetivo capacitar estudantes de graduação em Farmácia e Engenharia Agrícola e Ambiental, por meio de conhecimentos pertinentes às suas respectivas áreas de atuação profissional e nos temas em que os cursos se relacionam como a temática "acesso seguro e uso racional de plantas medicinais e de fitoterápicos". Além dessas atividades, o grupo tem como objetivo implementar e desenvolver o Programa Fitoterápico Farmácia Viva na Universidade Federal Fluminense (UFF) em parceria com a Fundação Municipal de Saúde de Niterói - cidade-sede da UFF - por meio das Unidades Básicas de Saúde. Para tanto, é imperativa a implementação das Boas Práticas de Cultivo, Processamento e Manipulação de Plantas Medicinais e de Fitoterápicos, em atendimento às prerrogativas da Agência Nacional de Vigilância Sanitária. Além de fornecer alternativas terapêuticas eficazes e de baixo custo, considerando a necessidade de ampliação de oferta de fitoterápicos e de plantas medicinais que atenda à demanda e às necessidades locais, é inerente às atividades do grupo, o conhecimento para o atendimento da legislação sanitária vigente no País e as necessidades do SUS.

O grupo tem objetivos também de disseminar, por meio de palestras, seminários, encontros científicos, minicursos, entre outros, os conhecimentos adquiridos e advindos das etapas de desenvolvimento do projeto e subprojetos no que se refere à preservação do meio ambiente, manejo sustentável, boas práticas agrícolas, boas práticas de fabricação e controle de fitoterápicos e de fitocosméticos, estudos farmacológicos e clínicos relacionados ao projeto, além do acesso seguro e uso racional de medicamentos.

\section{Agricultura Familiar}

Segundo definição da Organização das Nações Unidas para a Alimentação e Agricultura, “a Agricultura Familiar inclui todas as atividades agrícolas de base familiar e está ligada a diversas áreas do desenvolvimento rural. Consiste em um meio de organização das produções agrícola, florestal, pesqueira, pastoril e aquícola que são gerenciadas e operadas por uma família sendo, predominantemente, dependente de mão-de-obra familiar, tanto de mulheres quanto de homens." .

O ano de 2014 foi escolhido pela Organização das Nações Unidas como o ano da Agricultura Familiar e, em 25 de julho, comemora-se o Dia Internacional da Agricultura Familiar. Esses dois eventos simbólicos demonstram o fortalecimento crescente da Agricultura Familiar no panorama nacional e internacional. No Brasil, apesar da Agricultura Familiar ser responsável por 10\% do Produto Interno Bruto (PIB) e 33\% do PIB agropecuário (IBGE,2014), os agricultores enfrentam diversas dificuldades e desafios no que tange à organização, e comercialização da produção, falta de investimentos em infraestrutura, concorrência com grandes indústrias, entre outros.

Dados de 2015 (Portal Brasil) do Ministério do Desenvolvimento Agrário apontam que, 70\% dos gêneros alimentícios consumidos no país, são produzidos por Agricultores Familiares. Exemplos: 87\% da mandioca consumida no país é cultivada em propriedades familiares, feijão $(70 \%)$, carne suína $(59 \%)$, leite $(58 \%)$, carne de aves $(50 \%)$ e milho $(46 \%)$. Esses dados apontam a importância em se fomentar o desenvolvimento da Agricultura Familiar a qual, além da produção de alimento, gera 
emprego e renda para milhões de pessoas. (LOURENZANI, 2006). O desenvolvimento da Agricultura Familiar contribui para a formação de uma sociedade economicamente mais eficiente e socialmente mais justa (LOURENZANI, 2006). Atualmente, as pessoas têm-se preocupado, cada vez mais, com a preservação da biodiversidade e com o uso racional dos recursos naturais, um grande incentivo à implementação de atividades agrícolas baseadas na agroecologia (GUZMÁN, 1990; SHANIN, 1988 apud CAPORAL e COSTABEBER, 2001). Um dos objetivos da agroecologia é produzir avaliando as características da região e utilizando técnicas economicamente viáveis, socialmente justas e ecologicamente corretas (CHAGAS, 2015).

A introdução de plantas medicinais na Agricultura Familiar é um recurso interessante para os agricultores e para a sociedade. Ações coletivas podem ser promovidas numa comunidade de modo a conscientizar seus integrantes para viver com qualidade, fazendo uso racional e seguro dos recursos naturais disponíveis na prevenção ou combate aos males do cotidiano, em complementação ou substituição de alguns tratamentos convencionais. A introdução de plantas medicinais auxilia na educação ambiental, promovendo uma transformação sócio-político-cultural, a partir do resgate e da manutenção de valores tradicionais para com as famílias envolvidas (BORSATO et al, 2009).

No Brasil, fazem menção às plantas medicinais, a Política Nacional de Práticas Integrativas e Complementares no SUS - PNPIC (2006) e a Política Nacional de Plantas Medicinais e Fitoterápicos (2006). Ambas as políticas corroboram com a inserção dos agricultores familiares no cultivo de plantas medicinais. A PNPIC, por exemplo, preconiza a expansão do acesso dos pacientes do SUS às plantas medicinais e medicamentos fitoterápicos (SILVA e MORAES, 2008).

\section{Empoderamento}

Empoderar significa "ato ou efeito de dar ou adquirir poder ou mais poder" (PRIBERAM). O "empoderamento" é a possibilidade de fortalecimento dos agricultores familiares e de suas organizações, tanto individual (econômico) quanto coletivo (relacional), no ambiente em que estão inseridos (PEDINI; MACHADO, 2014). O tema tem sido pauta das agências de fomento, governamentais e não governamentais (ONGs), sobretudo, a partir da década de 1970 e, historicamente, tem vinculação com os movimentos sociais que militam em questões ligadas a gênero e raça, por exemplo, e mais recentemente, se tornou objeto de ação de organismos governamentais e multilaterais como o Banco Mundial (PEDINI e MACHADO, 2014).

Em algumas situações, percebe-se que os agricultores não possuem autonomia suficiente para administrar a produção e os recursos. Muitas vezes, os conhecimentos passados por meio das gerações, podem se mostrar ultrapassados e, em outros casos, os agricultores seguem as ordens de um superior, mas quando esses agricultores investem num negócio próprio ou recebem a função de gerenciar os recursos agrícolas, sentem dificuldades em iniciar tais atividades, ou mais precisamente, em organizar sua gestão, uma vez que não estão empoderados.

A aquisição plena e sensata de poder é realizada, em paralelo, com a difusão de conhecimento. A entidade encarregada da orientação dos agricultores é responsável por ensiná-los a pensar e a usar conhecimentos básicos e para que adquiram independência de logística futuramente. Sem esses conhecimentos prévios, tornam-se desmotivados e desanimados para a elaboração do plano de trabalho, uma vez que são intelectualmente dependentes de especialistas na área. A difusão do conhecimento é um dos aspectos do empoderamento que se encaixa no nível cognitivo (NYERERE, 1979). É importante ressaltar que os agricultores também são responsáveis por se auto empoderar.

Além do aspecto cognitivo, ou seja, da conscientização sobre a realidade e os processos, Nyerere aponta que o empoderamento envolve outros três seguintes níveis: $1^{\circ}$ Psicológico - ligado ao desenvolvimento de sentimentos de autoestima e autoconfiança, requisitos para a tomada de decisões; $2^{\circ}$ Econômico - que relaciona a importância da execução de atividades que possam gerar renda que assegure certo grau de independência econômica; $3^{\circ}$ Político - que envolve a habilidade para analisar e mobilizar o meio social para nele produzir mudanças. Ao nível psicológico, os agricultores precisam estar confiantes em aplicar o conhecimento que lhes for passado na prática, seguros de suas ações, mas conscientes da possibilidade de ocorrência de erros, pois serão introduzidos numa realidade, até então desconhecida, onde existirão desafios e dificuldades. Já no econômico, eles entendem que o objetivo final, sob responsabilidade deles, é gerar renda de forma sustentável, e que isso trará benefícios para toda a comunidade. Finalmente, ao nível político, eles adquirem senso crítico, fazem questionamentos e propõem mudanças, adaptações e inovações na comunidade. 


\section{Objetivos}

\section{Objetivo geral:}

Descrever as atividades do Grupo PET Farmácia Viva junto aos agricultores familiares da Cooperativa Univerde de Nova Iguaçu.

\section{Objetivos específicos:}

Revitalizar os procedimentos de cultivo e manejo das hortaliças cultivadas pelos agricultores; Introduzir o cultivo de plantas medicinais consorciadas com espécies alimentícias e aromáticas;

Promover a autonomia e o incremento de renda por meio de um planejamento estratégico participativo;

Empoderamento dos agricultores para a gestão da produção agrícola após o término da intervenção do grupo.

\section{Metodologia}

\section{Estabelecimento da parceria}

As comunidades de Geneciano Luz e Figueira (NI, RJ) e outras vizinhas, foram selecionadas pelo programa Petrobras Fome Zero, no ano de 2006, para o projeto "PAF-DUTOS Projeto Agricultura Familiar Agroecológica em Faixas de Dutos". O projeto consistiu em desenvolver o cultivo orgânico em faixas de dutos da Transpetro que cortam as propriedades, com geração de renda e sustentabilidade econômica para as famílias produtoras. O projeto preconizava a gestão de uma agroindústria, que futuramente seria gerenciada pela cooperativa Univerde e que serviria como fonte de aprendizagem para as famílias envolvidas e centro de referência para a Baixada Fluminense. Enquanto esteve vigente, $\mathrm{o}$ projeto gerou trabalho e renda para 16 famílias ligadas à cooperativa Univerde, promovendo a organização da produção e a comercialização da produção. Com o término do projeto em 2008, os agricultores sentiram-se carentes de autonomia sobre a organização da produção e sem empoderamento. Entre 2008 e 2012, houve redução substancial do número de famílias que trabalhavam na agricultura em faixas de dutos e elevada redução da renda familiar média mensal daquelas que permaneceram na atividade. (LANÇA, 2013)

As atividades de extensão realizadas pelo grupo PET Farmácia Viva da Universidade Federal Fluminense nas comunidades de Geneciano Luz e Figueira, no município de Nova Iguaçu (RJ), foram financiadas pelo Programa Fitoterápico Farmácia Viva da Universidade por meio do Prêmio Santander Universidade Solidária e da SENAES/MTE. O Programa Fitoterápico Farmácia Viva, coordenado pela tutora do grupo PET Farmácia Viva, teve início em 2012, levando em consideração, além do fortalecimento da agricultura familiar, o cultivo de uma espécie medicinal nativa de Mata Atlântica e em risco de erosão genética, a Ipecacuanha. A coordenadora geral do projeto se responsabilizou por iniciar os processos de sensibilização dos agricultores familiares da UNIVERDE, providenciar a infraestrutura e os materiais necessários para as atividades a serem desenvolvidas pelo grupo PET Farmácia Viva e pela administração dos recursos financeiros concedidos pelos financiadores do Programa Fitoterápico Farmácia Viva da UFF.

\section{Planejamento Estratégico e delineamento do estudo}

Em 2012, ano de início das atividades do grupo PET Farmácia Viva nas comunidades de agricultores, foi elaborado um planejamento estratégico para a retomada da produtividade agrícola. Priorizaram-se ações de capacitação dos agricultores, cultivo sustentável e a diversificação da produção, com a proposta de inserção de plantas medicinais.

O primeiro passo consistiu em estabelecer o diálogo com os produtores rurais. A equipe era formada por quatro engenheiros, dois farmacêuticos, dois técnicos agrícolas e 12 alunos (quatro do curso de Engenharia Agrícola e Ambiental e oito do curso de Farmácia). Os membros do grupo tinham a necessidade de agir com cautela, pois a experiência anterior dos agricultores, com grupos externos, sucedeu ruim. Havia a necessidade de se criar um ambiente no qual, os trabalhadores, se sentissem à vontade para conversar sobre o que já haviam aprendido, relatarem suas expectativas, fazerem críticas, contribuírem com sugestões e informações que permitissem ao grupo entender a situação atual dos agricultores. Era natural que oferecessem resistência a novas intervenções. Percebeu-se que uma 
abordagem correta é aquela na qual o produtor fala e a equipe escuta suas necessidades, histórias e dificuldades (CHAGAS, 2015).

As condições das propriedades foram conhecidas gradativamente, assim como as expectativas e anseios dos agricultores. Essa investigação se deu por meio do diálogo e, as informações mais importantes, foram obtidas por meio de um questionário. Com essas informações, e por meio da identificação das demandas da comunidade, os objetivos do projeto foram traçados com clareza, sempre com a participação da comunidade nas tomadas de decisão.

\section{Capacitações e troca de saberes}

A partir das sugestões dos agricultores, os profissionais envolvidos (Agrônomos, e Engenheiros Agrícolas e Ambientatis), reuniram-se para a elaboração das atividades de capacitação, determinando funções para os professores e alunos do grupo. As capacitações ficaram divididas por temas, como: segurança do trabalho, economia rural, controle alternativo e prevenção de pragas e doenças, cuidados e higiene com maquinários e equipamentos, propagação e produção e cultivo de mudas. Foram convidados professores colaboradores e técnicos agrícolas da Universidade Federal Fluminense, especialistas em cada um dos temas, para capacitar os agricultores. Estses, juntamente aos alunos do grupo PET, estiveram à disposição da comunidade para dúvidas, sendo as capacitações agendadas conforme a disponibilidade e locais sugeridos pelos produtores.

Foram desenvolvidas ações de capacitação por meio de minicursos realizados pelos professores colaboradores. Os temas eram sugeridos pelos integrantes do grupo PET e também pelos próprios agricultores, que reconheciam a necessidade de se capacitarem sobre determinados assuntos. Os agricultores adquiriram conhecimento teórico e prático nos minicursos. As atividades práticas possibilitaram aos agricultores vislumbrarem a aplicação da teoria na produção. Os objetivos dos temas abordados eram, além de proporcionar um convívio agradável entre os agricultores, integrantes e colaboradores do grupo PET, promover maior autonomia aos trabalhadores, deixando-os como atores principais na produção e permitindo que suas próprias ideias fossem colocadas em prática, com o auxílio dos membros do grupo PET.

Paralelamente, os alunos de farmácia avaliaram quais as plantas medicinais e aromáticas deveriam ser cultivadas em modelo consorciado, considerando-se suas propriedades medicinais, quais as condições necessárias para o cultivo (clima, solo, época de plantio, tratos culturais e, também, as formas farmacêuticas que poderiam ser utilizadas).

O cultivo e o manejo das plantas foram planejados com base nos conceitos propostos pela agroecologia, diante da necessidade de se praticar um manejo sustentável dos recursos no cotidiano da propriedade. Assim, foram feitas avaliações da fertilidade do solo, por meio de análises químicas de amostras do solo de diferentes lotes. Os agricultores, responsáveis por lote, foram devidamente capacitados e instruídos para que efetuassem a correção da fertilidade do solo. No manejo de pragas e doenças, realizado com a utilização de caldas vegetais e minerais, engenheiros agrícolas e agrônomos da UFF organizaram capacitações para que os agricultores aprendessem a preparar e a aplicar as caldas.

Com a finalidade de organizar os trabalhadores e a produção, as propriedades foram divididas em 10 lotes. Os produtores, responsáveis por cada lote, deviam mantê-lo limpo, organizado e preservado e, ainda, gerir a produção das hortaliças, de boa qualidade. Isso foi imensamente facilitado pelas ações de capacitação sobre vários temas realizados anteriormente (CHAGAS, 2015).

\section{Resultados e discussão}

\section{Dificuldades e desafios}

No decorrer da execução do projeto, algumas dificuldades foram encontradas. A desconfiança inicial, que os agricultores tinham do grupo, foi considerada normal. Os pequenos agricultores estavam descrentes de muitas entidades que estabeleciam parcerias, e depois de certo prazo, as encerravam sem trazer, de fato, resultados que não tornassem essas famílias tão dependentes desses convênios. Além disso, soma-se o choque natural entre pessoas de regiões carentes e estudantes universitários. Para superar esse desafio, o Grupo PET Farmácia Viva propôs vivências e imersões no cenário da comunidade, a fim de estabelecer melhores vínculos interpessoais. Gradualmente, os trabalhadores 
tornaram-se mais comunicativos, principalmente quando compreenderam que o projeto tinha como principal objetivo proporcionar melhorias para a comunidade. Assim, verificou-se que a abordagem ideal é aquela na qual há o estabelecimento de um consenso entre os produtores e o Grupo PET, equilibrando o conhecimento acadêmico e a vivência dos agricultores.

Outro desafio, para os gestores, foi o baixo orçamento disponível. A comunidade era, carente de recursos essenciais, para que os objetivos fossem alcançados. Dessa forma, foram estabelecidas porcentagens fixas para as despesas com as categorias: material de consumo (42\%), transporte e alimentação $(9 \%)$, serviços de terceiros $(20,2 \%)$ e material permanente e equipamento $(28,8 \%)$ (CHAGAS, 2015). Inclusive, surgiu a proposta de organização de uma feira agroecológica na UFF em Niterói, porém, devido a dificuldades burocráticas, não foi concluída.

Foi possível realizar plantio de espécies medicinais como romãzeira, espinheira-santa, citronela, boldo, erva cidreira, capim limão, saião, hortelã, jurubeba, alecrim, melissa, guaco, maracujá, quebrapedra, confrei, entre outras, consorciadas com espécies aromáticas e alimentícias. Diante do estabelecimento desse importante cenário, o Grupo PET Farmácia Viva passou a ter outro desafio, o de fortalecer a Política Nacional de Práticas Integrativas e Complementares no SUS (PNPIC), por meio de Arranjos Produtivos Locais (APL) de plantas medicinais e fitoterápicos. O projeto parou nestsa etapa, novamente, por conta de empecilhos burocráticos, e não chegou a implementar os APL.

\section{Resultados quantitativos e qualitativos}

Durante as visitas, observou-se que algumas hortaliças não se desenvolviam adequadamente e apresentavam baixa produtividade. Para a identificação do problema foram realizadas coletas de solo de diversos pontos do terreno; e, tais amostras, foram encaminhadas para um laboratório com fins de avaliar a fertilidade da área, por meio de análises física e química. Diante da carência de nutrientes essenciais no solo, os agricultores foram capacitados para efetuarem a correção e o problema foi solucionado. Eles receberam orientações para efetuarem o manejo alternativo de pragas. Outras práticas de manejo utilizadas foram a adubação verde, adubação orgânica, rotação de culturas, cobertura morta; consorciação de culturas; e caldas para manejo de pragas. A implementação dessas ações, resultou na melhoria da produtividade obtida na maioria dos lotes.

Após um primeiro momento de adaptação, tanto do Grupo PET quanto dos agricultores, a força de vontade e o compromisso deles com o trabalho, permitiu que o projeto fosse levado adiante, com resultados positivos, apesar das dificuldades encontradas. Percebia-se, neles, o desejo de investir nas culturas selecionadas, apesar da carência de recursos e de orientação técnica sobre o cultivo das mesmas. Entretanto, tais agricultores foram se tornando cada vez mais capacitados e aptos a gerir o trabalho na horta e na cooperativa, após cada visita do grupo.

A cooperativa UNIVERDE é formada, majoritariamente por mulheres (80\%), consideradas símbolo do trabalho no campo naquela região. Atualmente, com o planejamento estratégico e participação nas oficinas de capacitação, as mulheres conseguiram obter aumento na produtividade e melhoria da qualidade dos vegetais que cultivaram o que, em consequência, resultou na obtenção de grande parte do sustento e alimentação de suas famílias. De acordo com a análise da eficiência dos horticultores agroecológicos da cooperativa UNIVERDE, que levou em conta a renda bruta obtida, = a sazonalidade temporal, estabilidade dos lotes e a variedade e quantidade de produtos, foi observado; melhor rendimento comparativo, no lote de $n^{0} 6$, de março a dezembro de 2009 , com uma eficiência composta normalizada de 86,6\%, mesmo que tenha havido período sem assistência externa no referido ano - (OLIVEIRA et al, 2014). Esse lote de $\mathrm{n}^{\circ} 6$ tem como proprietárias mãe e filha, as quais, dividindo o serviço em horários alternados, conseguiam realizar as tarefas estabelecidas com muita organização e dedicação. Até mesmo, visualmente, seu lote era considerado modelo (SIQUEIRA, 2009).

Com os quatro níveis de empoderamento adotados como referência, pode-se afirmar que os agricultores passaram por um processo de transformação e tornaram-se empoderados, uma vez que, ao adquirirem conhecimento acerca das técnicas, se mostraram aptos a tomar decisões diante das mais diversas situações que surgiam. Tais agricultores conseguiram, também, a recuperação da sua renda mensal. Tornaram-se capazes de gerir a cooperativa UNIVERDE, sendo um modelo para novas imersões do grupo PET Farmácia Viva em comunidades de pequenos produtores rurais. 


\section{Conclusões}

As atividades de extensão, além dos inúmeros benefícios e experiências enriquecedoras ofertados aos membros da comunidade acadêmica, contribuem para o desenvolvimento da sociedade. Os recursos disponibilizados para a realização de projetos de extensão possibilitam à universidade atuar na formação de uma sociedade mais justa e igualitária, levando oportunidades à pessoas que vivem em realidades muito distintas.

Com otimização das técnicas de produção e administração dos agricultores das comunidades de Geneciano Luz e Figueira, tais agricultores se empoderaram e se tornaram aptos para a se organizarem e coordenar a produção. Os estudantes conseguiram articular seus conhecimentos e vivências da academia para o campo, dialogar com os pequenos produtores, além de estabelecer uma relação de confiança com todos os envolvidos no projeto.

\section{Fontes de financiamento}

O Ministério da Educação, concedeu bolsas ao tutor e alunos, além de verba de custeio.

O Ministério do Trabalho e Emprego, Ministério da Saúde e Universidade Federal Fluminense cederam recursos humanos, físicos e financeiros para viabilizar este projeto.

O Banco Santander premiou o grupo PET Farmácia Viva com o prêmio "Santander Universidade Solidária" em 2011, financiando as atividades do grupo junto as comunidades no biênio 2012-2013.

\section{Referências}

FERREIRA, A. B. H. Dicionário da língua portuguesa. 5. ed. Curitiba: Positivo, 2010. p. 2222.

BORSATO, A. V.; SILVA, A. DA.; SANTOS, A. G. dos.; JORGE, M. H. A.; Plantas medicinais e agroecologia: uma forma de cultivar o saber popular na região de Corumbá, MS. Corumbá: Embrapa Pantanal, 2009. Corumbá (MS), 2009. Disponível em: <http://www.cpap.embrapa.br/publicacoes/ online/DOC103.pdf>. Acesso em: 15 ago. 2016.

BRASIL. Portaria $n^{\circ}$ 976, de 27 de Julho de 2017. Diário Oficial da União, no 212 - 31 de outubro de 2013. Ministério da Educação, Poder Executivo - DF. 31 de out. de 2013. Seção 1, p. 40.

BRASIL. Ministério da Agricultura, Agropecuária e Abastecimento. Instituto Nacional de Metrologia. Monitoramento Climático de Municípios. Disponível em: <https://www.rio2016.com/ pregamestraining/sites/default/files/nova_iguacu_pt_1.pdf>. Acesso em: 15 out. de 2016.

BRASIL. Ministério da Saúde. Secretaria de Atenção à Saúde. Departamento de Atenção Básica. Política Nacional de Práticas Integrativas e Complementares no SUS - PNPIC-SUS / Ministério da Saúde, Secretaria de Atenção à Saúde, Departamento de Atenção Básica. - Brasília: Ministério da Saúde, 2006. Disponível em: <http://bvsms.saude.gov.br/bvs/publicacoes/pnpic.pdf>. Acesso em: 10 ago. de 2016.

CAPORAL, F. R.; CONTABEBER, J. A. Agroecologia e sustentabilidade base concentual para uma nova extensão rural. Santa Maria (RS), 2001. Grupo de Pesquisa Sociedade, Ambiente e Desenvolvimento Rural. Disponível em: <http://coral.ufsm.br/desenvolvimentorural/textos/13.pdf>. Acesso em: 28 ago. de 2016.

CHAGAS, E. L. O. F. Planejamento e Gestão Estratégica de um Projeto de Arranjo Produtivo Local de Plantas Medicinais: estudo de caso. Niterói: Escola de Engenharia. 20 p.(Monografia). 2015.

GUILHOTO, J. J. M; AZZONI, C. R.; SILVEIRA, F. G.; ICHIHARA, S. M.; DINIZ, B. P. C.; MOREIRA, G. C. R.; Ministério do Desenvolvimento Agrário. O Agronegócio Familiar no Brasil e nos seus Estados: A Contribuição da Agricultura Familiar para a Riqueza Nacional. São Paulo (SP), 2005. Disponível em: <https://goo.gl/Vawaw4>. Acesso em: 18 ago. 2016.

EMBRAPA, Empresa Brasileira de Pesquisa Agropecuária. Embrapa Agrobiologia. Ministério da Agricultura, Pecuária e Abastecimento. Agroecologia: princípios e técnicas para uma agricultura orgânica sustentável / editores técnicos, Embrapa Informação Tecnológica Brasília, DF 2005. 517 p. 
EMPODERAMENTO. Dicionário online Priberam, 04 de jun. 2017. Disponível em: <https:// www.priberam.pt/dlpo/empoderamento>. Acesso em: 4 jun. 2017.

IBGE, 2006. Censo agropecuário 2006. Disponível em: <https://goo.gl/CSHVF7>. Acesso em: 26 ago. 2016.

LANÇA, V. S., Desafio para Políticas de Apoio à Agricultura Familiar em Área Periurbana: O Caso da Cooperativa Univerde - Nova Iguaçu/RJ. Rio de Janeiro (RJ), 2013. 155 p.

LOBO, R. L.; SILVA, F.. Instituto Lobo. A Extensão Universitária: definição, propósitos, estratégias e ferramentas. Disponível em: <https://goo.gl/tFPXHR>. Acesso em: 17 ago. 2016.

LOURENZANI, W. L. Capacitação Gerencial de Agricultores Familiares: Uma Proposta Metodológica de Extensão Rural. Organizações Rurais \& Agroindustriais, Lavras, v. 8, n. 3, p. 313-322, 2006.

NYERERE, J. K. Unity for a New Order. In: HAQ, K. (Org.). Dialogue for a New Order. New York: Pergamon, 1979.

OLIVEIRA, E; ANDRADE, F. V. S.; MELLO, J. C. C. B. S.; MACHADO, T. B.; PEREIRA, C. R.; Avaliação da eficiência de horticultores agroecológicos utilizando análise envoltória de dados. Horticultura Brasileira. Vol.32, n03: 336-341 p.

SILVA, S. M. P.; MORAES, I. F. Agricultura familiar e o programa nacional de plantas medicinais e fitoterápicos: como a política pública poderá viabilizar esta cadeia produtiva. Revista Tecnologia $\mathcal{E}$ Inovação Agropecuária. Pindamonhangaba (SP), 2008. p. 67-76.

PEDINI, S.; MACHADO, R. T. M. Fair Trade: possibilidades de empoderamento de cafeicultores familiares no sul de Minas Gerais. Estudos de Sociedade e Agricultura, Rio de Janeiro, vol. 22, n. 2, 2014: 457-481 p.

PETROBRAS, Agricultura Familiar em Faixa de Dutos - Manual Metodológico, Rio de Janeiro, 2007. Disponível em: <https://goo.gl/xiubCI>. Acesso em: 20 out. 2016.

PORTAL BRASIL, Agricultura familiar produz 70\% dos alimentos consumidos por brasileiros. Disponível em: <http://www.brasil.gov.br/economia-e-emprego/2015/07/agricultura-familiar-produz70-dos-alimentos-consumidos-por-brasileiros>. Acesso em: 4 jun. 2017.

Recebido para publicação em 30/10/2016 e aprovado em 9/6/2017. 